\title{
Birth of a solid organ cancer-the cell fusion hypothesis presented with pancreatic cancer as a model: a narrative review
}

\author{
Savio G. Barreto ${ }^{1,2}$, Nilesh Gardi ${ }^{3,4}$, Shilpee Dutt ${ }^{4,5}$ \\ ${ }^{1}$ Division of Surgery and Perioperative Medicine, Flinders Medical Centre, Bedford Park, Adelaide, South Australia, Australia; ${ }^{2}$ College of Medicine \\ and Public Health, Flinders University, Bedford Park, Adelaide, South Australia, Australia; ${ }^{3}$ Department of Medical Oncology, Tata Memorial \\ Hospital, Tata Memorial Centre, Mumbai, India; ${ }^{4}$ Homi Bhabha National Institute, Training School Complex, Anushakti Nagar, Mumbai, India; \\ ${ }^{5}$ Shilpee Dutt Laboratory, Advanced Centre for Treatment, Research and Education in Cancer (ACTREC), Tata Memorial Centre, Kharghar, Navi \\ Mumbai, India \\ Contributions: (I) Conception and design: SG Barreto; (II) Administrative support: None; (III) Provision of study materials or patients: None; (IV) \\ Collection and assembly of data: N Gardi, S Dutt; (V) Data analysis and interpretation: SG Barreto, S Dutt; (VI) Manuscript writing: All authors; (VII) \\ Final approval of manuscript: All authors. \\ Correspondence to: Savio G. Barreto. Department of Surgery, Flinders Medical Centre, Bedford Park, South Australia 5042, Australia. Email: \\ georgebarreto@yahoo.com; savio.barreto@sa.gov.au; Shilpee Dutt. Principal Investigator, Advanced Centre for Training, Research and Education in \\ Cancer (ACTREC), Sector 21, Kharghar, Navi Mumbai 410210, India. Email: sdutt@actrec.gov.in; drshilpeedutt@gmail.com.
}

\begin{abstract}
Objective: This hypothesis-driven narrative review aims to explore the evidence for the fundamental process of cell fusion between normal, but different, cell types in the genesis of a cancer cell.

Background: Finding out how a cancer is born must remain a top priority as this will allow us the opportunity to understand the disease before it acquires its largely 'untameable' heterogeneous form. The search for the cell of origin in solid organ cancers has remained elusive despite concerted attempts over many decades. There is always more than one cell type implicated in the causation of solid organ cancers.

Methods: Based on preliminary data from our laboratory and a review of the evidence in literature, we present a novel hypothesis to explain the origin of solid organ cancers using pancreatic cancer as an example. Conclusions: We hypothesize that, "Cancer is born from fusion and bybridization of normal cells from two different lineages located within the vicinity of each other that perceive a signal reminiscent of a threat to their extinction that leads to epigenetically-mediated transformations permitting them to achieve cell fusion." Addressing this hypothesis to prove, or disprove it, presents an opportunity to unravel the basis of carcinogenesis and potential re-think our strategies for treatment in terms of choice of chemotherapeutic agents, dosage of chemo- and radiation-therapy, and timing of interventions (surgery, chemotherapy and radiation therapy).
\end{abstract}

Keywords: Cells; outcomes; theory; neoplasm; cell fusion

Submitted Jun 06, 2021. Accepted for publication Sep 17, 2021.

doi: 10.21037/cco-21-69

View this article at: https://dx.doi.org/10.21037/cco-21-69

\section{Introduction}

The search for the cell of origin in solid organ cancers has remained elusive despite concerted attempts over many decades. There is always more than one cell type implicated in the causation of solid organ cancers (1-4) and while carcinogenesis may be eloquently described in some cancers (5-7), there remains much to be elucidated. The availability of large amounts of genomic data from tumour sequencing is currently exceeding the analytical capabilities of bioinformatic platforms (8). And while it is only a matter of time before this hurdle is overcome, inherent tumour heterogeneity has made the deciphering of driver events a difficult task at the present time (8-10).

Finding out how a cancer is born must remain a top priority as this will allow us the opportunity to understand 
the disease before it acquires its largely "untameable" heterogeneous form. More importantly, this information will help us to decipher what caused it to develop in the first place-providing us a real opportunity to prevent the disease that is ranked $6^{\text {th }}$ amongst the leading killers of humanity (11).

Cell fusion between tumour-normal and tumourtumour cells have been reported in some of the cancers as key events that mediate cancer progression, therapeutic resistance and metastasis $(12,13)$. While studying the evolution of resistance in cancer using glioblastoma, we have also reported that glioma cells that survive the initial onslaught of a lethal dose of radiation undergo homotypic cell fusion that gives the hybrid cells [multinucleated and giant cells (MNGCs)] survival advantage (14). This is the first report that identified radiation-induced homotypic cell fusions of resistant residual glioma cells as a novel non-genetic mechanism to sustain survival and relapse. Further, we have also shown that the progeny of the hybrid cells acquires epigenetic modifications that help them survive radiation induced DNA damage and acquire novel aggressive phenotype (invasion and migration) $(15,16)$. Presence of the hybrid cells is also associated with poor survival of glioblastoma patients (17). To understand the mechanism of survival of hybrid cells, we performed total proteome and transcriptome analysis of these cells. Interestingly we found many developmental pathways to be upregulated in the fused multinucleated cells (18). These data provide evidence that homotypic fusion of cancer cell is a mechanism that helps the hybrid cell to evolve and survive under stressful conditions. While our, and other, studies in literature report the possibility of fusion events between cancer cells, or cancer and normal cells during cancer progression, we postulate that the fundamental process of cell fusion between normal cells is involved in the genesis of a cancer cell. We present the following article in accordance with the Narrative Review reporting checklist (available at https://dx.doi.org/10.21037/cco-21-69).

\section{Hypothesis}

"Cancer is born from a fusion of cells from two different lineages located within the vicinity of each other that perceive a signal reminiscent of a threat to their extinction that leads to epigenetically-mediated nuclear reprograming within each of them to induce heterotypic cell fusion." The aim of this cell fusion is for the parent cells to transfer to their progeny what they are programmed to believe would be the "ideal" genetic and epigenetic make-up required for the progeny to survive the conditions of stress. The progeny, so formed, bear new traits acquired by parasexual recombination of parent cells. These cells then continue the process of homotypic or heterotypic cell fusion when faced with severe stress, lead ultimately to the generation of a heterogeneous cell population in which none of the clones resemble the "parent" cell.

Here we propose to test our hypothesis using pancreatic cancer as a model system.

\section{Rationale for the hypothesis and choice of pancreatic cancer as a model system}

Pancreatic cancer is one of the most lethal cancers in the world currently ranked as the $4^{\text {th }}$ leading cause for cancer mortality in the developed world (19). In India, the incidence ranges from $0.5-2.4 / 100,000(20,21)$. These levels may be the result of under reporting of the cancer (22). Besides, there has been a significant increase in mean percentage change in disease-adjusted life years for pancreatic cancer in India from 1990 to 2016 (22). In Australia, it is estimated that by the age of 85,1 in 54 for Australian men and 1 in 70 Australian women will be diagnosed with the disease (23). There has been a significant increase in incidence and mortality from the disease over the last 3 decades (24). The 5 -year survival rates for pancreatic cancer are amongst the lowest of all cancers in Australia [9.1\% for men and $9.2 \%$ for women (25)]. It is thus a cancer of significant importance that warrants further research.

Our hypothesis was born from a combination of our experimental data from glioblastoma in which the stress (radiation)-induced homotypic cell fusion (14), as well as the detailed understanding of the confusion in the origins of pancreatic cancer. The stressors (hyperglycaemia, hypoxia, metabolites of cigarette smoke, etc.) that we anticipate as being causative in the process of heterotypic cell fusion are postulated to be risk factors for pancreatic cancer. Hence, we present the hypothesis using the pancreas as a model.

\section{In pancreatic cancer, different cell types have been experimentally proposed to be the progenitor cell for carcinogenesis}

While pancreatic cancer is referred pathologically as pancreatic ductal adenocarcinoma (PDAC) because of its morphology, other cell types have been proposed to be the 
cell of origin $(3,26)$. Broadly, the two proposed sources of the progenitor cell of pancreatic cancer are of:

Endocrine origin: in the experimental BOP [N-nitrosobis (2-hydroxypropyl) amine (DIPN)] model of pancreatic carcinogenesis (27) there is compelling evidence that the islets are required for carcinogenesis $(4,28)$. A cell derived from the islets of Langerhans $(4,28)$ — possibly a $\beta$-cell (2) seems the most likely.

Exocrine origin: the "acinar to ductal" carcinogenesis model based on a malignant transformation of the acinar/ centro-acinar cells (29).

The problem with both these theories (with respect to pancreatic cancer) is that the "progeny"-PDAC (most common form of the cancer) - a cell with phenotypic similarities to the ductal tissue is, in itself, refractory to induction of pancreatic neoplasia (26). Interestingly, though, although it does not phenotypically resemble the proposed parent cells, it possesses genetic signatures of the parents (3), namely, SOX-9 of the acinar cell (26) and LGR5 and Nanog of islet origin (2).

\section{Is such a "union" even possible?}

Reproduction can be sexual, asexual or parasexual with sexual being the dominant form in humans and animals (30). Sexual reproduction facilitates adaptation (31) by enabling the cell to overcome negative linkages that tend to accumulate over time within finite populations subjected to the process of selection (32) and help impart genetic mixing $(33,34)$ to enable the species to overcome complex environments (as noted above). The ubiquitous human pathogen, Candida albicans, has been known to undergo recombination in a parasexual (recombination of genes from different individuals but does not involve meiosis and formation of a zygote by fertilization as in sexual reproduction) manner $(35,36)$. Five decades ago, it was demonstrated that human cells have the ability (with the appropriate stimuli) to undergo parasexual recombination (37). We refer to the process as reproduction, in order to clarify its difference from recombination, a phenomenon that occurs in somatic cells of eukaryotes and is well known in cancer mutagenesis (38). The word, "reproduction", used by us, is meant to suggest a union for the sake of recombination between cells of different lineages.

\section{What events could drive such a transformation?}

As early as the 1930s, Fisher (39) and Muller (40) proposed a theory that within finite populations exposed to "new" environments, sexual recombination would afford the best chance at adaptation by permitting beneficial mutations that arise on different chromosomes to be brought together on the same chromosome (41). These rates increase in complex (31) or spatially heterogenous environments (42) - as was demonstrated in the species Brachionus calyciflorus exposed to high- and low-quality foods.

Zhou et al. (43) from the laboratory of Jeffrey Platt in Michigan demonstrated that by injecting cells from a pool of fused, but not cloned, IEC-6 cells when injected into the flanks of immunodeficient mice, 11 of the 18 injections generates tumours. However, none in the unmodified IEC6 cells, nor from the non-fused clones, generated tumours. The authors concluded that cell fusion is associated with oncogenesis. However, these experiments did not demonstrate the role for cell fusion as the initiating event in carcinogenesis. As pointed out by Platt and Cascalho (44), it has been a challenge to demonstrate cell fusion, or the formation of hybrids, in normal tissues in the absence of markers, other than the presence of multiple nuclei. We postulate the effect of stressors on cell fusion for two reasons, namely, our own experience with radiation leading to the generation of hybrids (mentioned above) (14) as well as evidence in literature, including the effect of mechanical stress driving cell fusion (45) and nutrient depletion (and hypoxia) leading to the formation of immature, stem cell phenotype in neuroblastomas (46).

In pancreatic cancer, the relationship of cancer and diabetes mellitus is well appreciated. It is uncertain if diabetes mellitus is the cause, or the effect, of pancreatic cancer mediated through the destruction of the $\beta$-cells of the islets (47). Schneider and colleagues (48) studied the effects of metformin, an oral diabetic medication, in an experimental model of pancreatic carcinogenesis. They divided high-fat fed hamsters into two groups. The treatment group received metformin in drinking water for 42 weeks while the control group did not. Once the plasma insulin levels normalised (after 2 weeks of metformin), both groups were treated with BOP for 2 weeks. While $50 \%$ of the control group developed PDAC, no cancers were found in the control group $(\mathrm{P}<0.05)$. This study provides evidence that the excess nutrient load (which would be regarded as generally unhealthy in humans and animals alike) that served to increase pancreatic carcinogenesis in this experimental model would lead the cells to perceive their new environment as heterogenous - a potential trigger for reproduction. Clinically, type II diabetes mellitus (49) and obesity (50), two diseases characterised by nutrient 
excess, have been very closely linked to the development of pancreatic cancer.

\section{What is the evidence in cancers that further "union" occurs between these progeny cells?}

Progression in cancer is noted histologically as grades of differentiation-resemblance of the cancer cell to the parent cell from which it is believed to be derived. Traditional pathological teaching subclassifies these as well, moderatelywell, and poorly differentiated denoting a progressive dissimilarity to the parent cell (51). Stress responses such as hypoxia encountered when the proliferation of cells exceeds the nutrient load available has been shown to promote an immature, stem-cell phenotype in some cancers such as neuroblastomas (46). In pancreatic cancer, hypoxia leads to increased tumour invasion and metastases (52). Hypoxia has been shown to induce cell fusion in solid organ cancers $(53,54)$. And it is, thus, not unreasonable to assume that the progeny cells starved of oxygen may revert to cell fusion to survive with the steady accumulation of deleterious mutations.

\section{How does this hypothesis align with existing theories of carcinogenesis?}

The proposed hypothesis presents a unification of previously proposed theories of carcinogenesis, namely, the cell-based [somatic mutation theory (55)] and the tissue-based (56) theories. The tissue organisation field theory revolves around chronic abnormal interactions between the mesenchyme/ stroma and the parenchyma of a given morphogenic field resulting in a tumour (57). It posits that carcinogenesis represents a problem of tissue organization, comparable to organogenesis, and that proliferation is the default state of all cells (57). The "reproduction or cell fusion" hypothesis proposed here acknowledges the relevance of interactions of different components of a tissue (56) as a precursor to the fusion of cells from two different lineages. It also aligns with Potter's hypothesis that an organ consists of a population of cells that are participating in an organized and orchestrated programme which takes them through a sequence of changes that are constantly tailored to make the organ as adaptive as possible to the range of environmental variation in which it evolved (58). We posit that the ensuing progeny cell derived from this union can express somatic mutations, the "hallmark" of the cell-based theory (55). Martins-Chaves et al. (59) have shown that even non-malignant multinucleated cells present within a granuloma forming in response to a dental implant can express $K R A S$ mutations and be associated with the activation of the MAPK-ERK signalling pathways. In fact, this process has a shared histogenesis with PDAC (60). These progeny or initiated cells in a promoted mass accrue additional stable genetic or epigenetic changes acquiring the ability to block gap junctional intercellular communications (GJIC) (61) thereby entering the stage of progression of carcinogenesis (62).

\section{Clinical relevance of the proposed hypothesis}

The hypothesis presented in this manuscript enables a clearer understanding of the process of immune editing eloquently conceptualised by Dunn et al. (63) to explain how cancer cells can progress beyond immune surveillance. Alterations in expression of major histocompatibility complex (MHC) molecules play a crucial step in tumour development due to the role of MHC antigens in antigen presentation to T-lymphocytes and the regulation of natural killer cell (NK) cell function (64). Cell fusion alters the characteristics of cell surface receptors, including MHC proteins (65) with the potential to interfere with their immune regulatory function. Extensive genomic diversification is another potential postulated strategy for tumour cells formed from cell fusion to escape immune control (66). Further, Gupta et al. (67) have also noted that cancer stem-like cells can arise de novo from nonstem-like cells at a low, but significant rate. The proposed hypothesis also aligns with the concept of intrinsic factors, such as (perceived) genomic instability, resulting in tumour heterogeneity (68), an important cause for resistance to chemotherapy. The impact of radiation therapy on the cellular and tumour microenvironment with the resultant alterations in tissue composition and the physical interactions and signalling between cells is known (69). As noted by us (14), and others (70), radiation exposure to cells results in multinucleated giant cancer cells. Subtherapeutic levels of radiation are thus not only capable of inducing carcinogenesis, but have even been shown to facilitate tumour cell migration and metastases (71).

In 1976, Peter Nowell (72) first postulated that neoplasms arise from a single cell of origin, and the original clone, through sequential selection, follows an evolutionary trajectory resulting in cellular heterogeneity. Our present understanding of carcinogenesis leads us to infer that inter-, and intra-, tumour heterogeneity are the main obstacles to the successful eradication of cancer. The perceived so- 
called protective mechanisms/agents against neoplastic progression and evolution include limited availability of nutrients for rapidly proliferating cells, immune surveillance, hypoxia in the local tumour milieu, relative geographic isolation, and treatment modalities including chemo- and radiation therapy. Here we hypothesize that as part of a process of adaptation against selective pressures, somatic or parental cells fuse via parasexual reproduction with the resultant progeny cells possessing a survival advantage over the parent cells in terms of proliferative and invasive capabilities.

Although the above discussion is convincing for a potential role of cell fusion in carcinogenesis, the reality lies in the fact that outside of the experimental arena, there is scarce morphological evidence of cell fusion in neoplastic tissues. The only available clinical evidence, at the present time, is based on the analysis of short tandem repeats (STRs) in micro-dissected tumour cells of male melanoma patients who received a bone marrow transplant (BMT) from their siblings. The researchers were able to demonstrate an overlay of various donor and pre-BMT recipient alleles $(73,74)$.

\section{Experimental strategy}

\section{Mining the publicly available data}

The first strategy we plan to employ is single cell transcriptomics for lineage tracing. Here we will analyse the single cell (PDAC) transcriptome database to determine if it contains genetic signatures of acinar cells and islets, or acinar and centro-acinar cells, or centro-acinar cells and islets.

\section{Experimental proof (generation of the model)}

We plan to co-culture various combinations of isolated acinar cells, centro-acinar cells and islets (acinar + islets; acinar + centro-acinar cells; centro-acinar cells + islets) and under different culture media conditions (stressors) like high concentrations of glucose, and/or metabolites of cigarette smoke, and/or inducing hypoxia. We will also plan to expose these cell cultures to graded doses of radiation from sublethal to lethal. The aim of this experiment would be to assess if cell fusion occurs in stressful conditions. Different cell types will be labelled with different colour fluorescent markers to analyse the fusion events. The hybrid cells will be sorted by flowcytometry and assessed by karyotyping, histology and whole genome sequencing.

\section{Exploring the concept using models of step-wise carcinogenesis}

Central to the hypothesis in this manuscript is the ability to prove cell fusion as the initiating event in carcinogenesis. Thus, mere demonstration of evidence of cell fusion in malignant cells or metastases, is inadequate. The use of step-wise models of carcinogenesis hold the promise of providing the required evidence. While the authors are working on developing their own model of carcinogenesis, currently available evolutionary models such as those developed by Vincent and Gatenby $(75,76)$ could offer an opportunity to test this hypothesis.

\section{Conclusions}

In conclusion, we present a testable hypothesis to explain not only the origins of solid organ cancers, but also their ability to escape immune surveillance, develop resistance to cell-directed therapies, and inexplicable deterioration in local control and distant metastases despite radiation therapy that has been observed. Addressing this hypothesis to prove, or disprove it, presents an opportunity to unravel the basis of carcinogenesis and potential rethink our strategies for treatment in terms of choice of chemotherapeutic agents, dosage of chemo- and radiationtherapy, and timing of interventions (surgery, chemotherapy and radiation therapy).

\section{Acknowledgments}

Funding: None.

\section{Footnote}

Provenance and Peer Review: This article was commissioned by the editorial office, Chinese Clinical Oncology for the series "Unresolved Issues in Pancreatic Cancer". The article has undergone external peer review.

Reporting Checklist: The authors have completed the Narrative Review reporting checklist. Available at https:// dx.doi.org/10.21037/cco-21-69

Conflicts of Interest: All authors have completed the ICMJE uniform disclosure form (available at http://dx.doi. 
org/10.21037/cco-21-69). The series "Unresolved Issues in Pancreatic Cancer" was commissioned by the editorial office without any funding or sponsorship. Dr. SGB served as the unpaid Guest Editor of the series, and serves as an unpaid editorial board member of Chinese Clinical Oncology. The authors have no other conflicts of interest to declare.

Ethical Statement: The authors are accountable for all aspects of the work in ensuring that questions related to the accuracy or integrity of any part of the work are appropriately investigated and resolved.

Open Access Statement: This is an Open Access article distributed in accordance with the Creative Commons Attribution-NonCommercial-NoDerivs 4.0 International License (CC BY-NC-ND 4.0), which permits the noncommercial replication and distribution of the article with the strict proviso that no changes or edits are made and the original work is properly cited (including links to both the formal publication through the relevant DOI and the license). See: https://creativecommons.org/licenses/by-nc-nd/4.0/.

\section{References}

1. Hanna JM, Onaitis MW. Cell of origin of lung cancer. J Carcinog 2013;12:6.

2. Amsterdam A, Raanan C, Schreiber L, et al. LGR5 and Nanog identify stem cell signature of pancreas beta cells which initiate pancreatic cancer. Biochem Biophys Res Commun 2013;433:157-62.

3. Maitra A, Leach SD. Disputed paternity: the uncertain ancestry of pancreatic ductal neoplasia. Cancer Cell 2012;22:701-3.

4. Pour PM, Weide L, Liu G, et al. Experimental evidence for the origin of ductal-type adenocarcinoma from the islets of Langerhans. Am J Pathol 1997;150:2167-80.

5. Barreto SG, Dutt A, Chaudhary A. A genetic model for gallbladder carcinogenesis and its dissemination. Ann Oncol 2014;25:1086-97.

6. Fearon ER, Vogelstein B. A genetic model for colorectal tumorigenesis. Cell 1990;61:759-67.

7. Maitra A, Kern SE, Hruban RH. Molecular pathogenesis of pancreatic cancer. Best Pract Res Clin Gastroenterol 2006;20:211-26.

8. Suwinski P, Ong C, Ling MHT, et al. Advancing Personalized Medicine Through the Application of Whole Exome Sequencing and Big Data Analytics. Front Genet 2019;10:49.
9. Gerlinger M, Rowan AJ, Horswell S, et al. Intratumor heterogeneity and branched evolution revealed by multiregion sequencing. N Engl J Med 2012;366:883-92.

10. McGranahan N, Swanton C. Biological and therapeutic impact of intratumor heterogeneity in cancer evolution. Cancer Cell 2015;27:15-26.

11. The top 10 causes of death. World Health Organization, 2018. Available online: https://www.who.int/news-room/ fact-sheets/detail/the-top-10-causes-of-death

12. Weiler J, Dittmar T. Cell Fusion in Human Cancer: The Dark Matter Hypothesis. Cells 2019;8:132.

13. Shabo I, Svanvik J, Lindström A, et al. Roles of cell fusion, hybridization and polyploid cell formation in cancer metastasis. World J Clin Oncol 2020;11:121-35.

14. Kaur E, Rajendra J, Jadhav S, et al. Radiation-induced homotypic cell fusions of innately resistant glioblastoma cells mediate their sustained survival and recurrence. Carcinogenesis 2015;36:685-95.

15. Kaur E, Sahu A, Hole AR, et al. Unique spectral markers discern recurrent Glioblastoma cells from heterogeneous parent population. Sci Rep 2016;6:26538.

16. Kaur E, Nair J, Ghorai A, et al. Inhibition of SETMARH3K36me2-NHEJ repair axis in residual disease cells prevents glioblastoma recurrence. Neuro Oncol 2020;22:1785-96.

17. Kaur E, Goda JS, Ghorai A, et al. Molecular features unique to glioblastoma radiation resistant residual cells may affect patient outcome - a short report. Cell Oncol (Dordr) 2019;42:107-16.

18. Rajendra J, Datta KK, Ud Din Farooqee SB, et al. Enhanced proteasomal activity is essential for long term survival and recurrence of innately radiation resistant residual glioblastoma cells. Oncotarget 2018;9:27667-81.

19. Maisonneuve P. Epidemiology and burden of pancreatic cancer. Presse Med 2019;48:e113-23.

20. Shrikhande SV, Barreto SG, Somashekar BA, et al. Evolution of pancreatoduodenectomy in a tertiary cancer center in India: improved results from service reconfiguration. Pancreatology 2013;13:63-71.

21. Shrikhande S, Barreto S, Sirohi B, et al. Indian council of medical research consensus document for the management of pancreatic cancer. Indian J Med Paediatr Oncol. 2019;40:9-14.

22. India State-Level Disease Burden Initiative Cancer Collaborators. The burden of cancers and their variations across the states of India: the Global Burden of Disease Study 1990-2016. Lancet Oncol 2018;19:1289-306.

23. Cancer Council Australia. Pancreatic Cancer. Available 
online: https://www.cancer.org.au/about-cancer/types-ofcancer/pancreatic-cancer.html

24. Cocker F, Chien Yee K, Palmer AJ, et al. Increasing incidence and mortality related to liver cancer in Australia: time to turn the tide. Aust N Z J Public Health 2019;43:267-73.

25. Australian Institiute of Health and Welfare. Available online: https://www.aihw.gov.au/getmedia/7beca2c1b0dd-40b5-ad2b-cf4dfc6a4796/aihw-aus-221chapter-3-4.pdf.aspx

26. Kopp JL, von Figura G, Mayes E, et al. Identification of Sox9-dependent acinar-to-ductal reprogramming as the principal mechanism for initiation of pancreatic ductal adenocarcinoma. Cancer Cell 2012;22:737-50.

27. Levitt MH, Harris CC, Squire R, et al. Experimental pancreatic carcinogenesis. I. Morphogenesis of pancreatic adenocarcinoma in the Syrian golden hamster induced by N-nitroso-bis(2-hydroxypropyl)amine. Am J Pathol 1977;88:5-28.

28. El-Ghamari M, Bergmann F, Schmied BM, et al. Islet cells contribute to pancreatic carcinogenesis in an animal model. Pancreas 2011;40:242-6.

29. Aichler M, Seiler C, Tost M, et al. Origin of pancreatic ductal adenocarcinoma from atypical flat lesions: a comparative study in transgenic mice and human tissues. J Pathol 2012;226:723-34.

30. Dimijian GG. Evolution of sexuality: biology and behavior. Proc (Bayl Univ Med Cent) 2005;18:244-58.

31. Luijckx P, Ho EK, Gasim M, et al. Higher rates of sex evolve during adaptation to more complex environments. Proc Natl Acad Sci U S A 2017;114:534-9.

32. Hill WG, Robertson A. The effect of linkage on limits to artificial selection. Genet Res 2007;89:311-36.

33. Barton NH, Otto SP. Evolution of recombination due to random drift. Genetics 2005;169:2353-70.

34. Felsenstein J. The evolutionary advantage of recombination. Genetics 1974;78:737-56.

35. Wang JM, Bennett RJ, Anderson MZ. The Genome of the Human Pathogen Candida albicans Is Shaped by Mutation and Cryptic Sexual Recombination. mBio 2018;9:01205-18.

36. Bennett RJ. The parasexual lifestyle of Candida albicans. Curr Opin Microbiol 2015;28:10-7.

37. Martin GM, Sprague CA. Parasexual cycle in cultivated human somatic cells. Science 1969;166:761-3.

38. Cerbinskaite A, Mukhopadhyay A, Plummer ER, et al. Defective homologous recombination in human cancers. Cancer Treat Rev 2012;38:89-100.
39. Fisher R. The genetical theory of natural selection. 2 edition. Oxford: Clarendon Press, 1930.

40. Muller H. Some genetic aspects of sex. Am Nat 1932;66:118-38.

41. Kim Y, Orr HA. Adaptation in sexuals vs. asexuals: clonal interference and the Fisher-Muller model. Genetics 2005;171:1377-86.

42. Becks L, Agrawal AF. Higher rates of sex evolve in spatially heterogeneous environments. Nature 2010;468:89-92.

43. Zhou X, Merchak K, Lee W, et al. Cell Fusion Connects Oncogenesis with Tumor Evolution. Am J Pathol 2015;185:2049-60.

44. Platt JL, Cascalho M. Cell Fusion in Malignancy: A Cause or Consequence? A Provocateur or Cure? Cells 2019;8:587.

45. Kim JH, Ren $\mathrm{Y}, \mathrm{Ng} W \mathrm{P}$, et al. Mechanical tension drives cell membrane fusion. Dev Cell 2015;32:561-73.

46. Höckel M, Vaupel P. Tumor hypoxia: definitions and current clinical, biologic, and molecular aspects. J Natl Cancer Inst 2001;93:266-76.

47. Hayashida CY, Suzuki K, Fujiya H, et al. Morphometrical quantitation of pancreatic endocrine cells in patients with carcinoma of the pancreas. Tohoku J Exp Med 1983;141:311-22.

48. Schneider MB, Matsuzaki H, Haorah J, et al. Prevention of pancreatic cancer induction in hamsters by metformin. Gastroenterology 2001;120:1263-70.

49. Michaud DS. Obesity and Pancreatic Cancer. Recent Results Cancer Res 2016;208:95-105.

50. Bracci PM. Obesity and pancreatic cancer: overview of epidemiologic evidence and biologic mechanisms. Mol Carcinog 2012;51:53-63.

51. Jögi A, Vaapil M, Johansson M, et al. Cancer cell differentiation heterogeneity and aggressive behavior in solid tumors. Ups J Med Sci 2012;117:217-24.

52. Yuen A, Díaz B. The impact of hypoxia in pancreatic cancer invasion and metastasis. Hypoxia (Auckl) 2014;2:91-106.

53. Mattson VR, Russell Hockett J, Highland TL, et al. Effects of low dissolved oxygen on organisms used in freshwater sediment toxicity tests. Chemosphere 2008;70:1840-4.

54. Jiang E, Yan T, Xu Z, et al. Tumor Microenvironment and Cell Fusion. Biomed Res Int 2019;2019:5013592.

55. Boveri T. The Origin of Malignant Tumors. Baltimore, MD: Williams \& Wilkins, 1929.

56. Soto AM, Sonnenschein C. The tissue organization field theory of cancer: a testable replacement for the somatic mutation theory. Bioessays 2011;33:332-40. 
57. Soto AM, Sonnenschein C. The somatic mutation theory of cancer: growing problems with the paradigm? Bioessays 2004;26:1097-107.

58. Potter VR. Phenotypic diversity in experimental hepatomas: the concept of partially blocked ontogeny. The 10th Walter Hubert Lecture. Br J Cancer 1978;38:1-23.

59. Martins-Chaves RR, Guimarães LM, Pereira TDSF, et al. KRAS mutations in implant-associated peripheral giant cell granuloma. Oral Dis 2020;26:334-40.

60. Gocke CD, Dabbs DJ, Benko FA, et al. KRAS oncogene mutations suggest a common histogenetic origin for pleomorphic giant cell tumor of the pancreas, osteoclastoma of the pancreas, and pancreatic duct adenocarcinoma. Hum Pathol 1997;28:80-3.

61. Loewenstein WR. Permeability of membrane junctions. Ann N Y Acad Sci 1966;137:441-72.

62. Trosko JE, Chang CC, Upham BL, et al. Ignored hallmarks of carcinogenesis: stem cells and cell-cell communication. Ann N Y Acad Sci 2004;1028:192-201.

63. Dunn GP, Bruce AT, Ikeda H, et al. Cancer immunoediting: from immunosurveillance to tumor escape. Nat Immunol 2002;3:991-8.

64. Garcia-Lora A, Algarra I, Garrido F. MHC class I antigens, immune surveillance, and tumor immune escape. J Cell Physiol 2003;195:346-55.

65. Nagy P, Mátyus L, Jenei A, et al. Cell fusion experiments reveal distinctly different association characteristics of cellsurface receptors. J Cell Sci 2001;114:4063-71.

66. Platt JL, Zhou X, Lefferts AR, et al. Cell Fusion in the War on Cancer: A Perspective on the Inception of Malignancy. Int J Mol Sci 2016;17:1118.

67. Gupta PB, Fillmore CM, Jiang G, et al. Stochastic

Cite this article as: Barreto SG, Gardi N, Dutt S. Birth of a solid organ cancer-the cell fusion hypothesis presented with pancreatic cancer as a model: a narrative review. Chin Clin Oncol 2021;10(5):45. doi: 10.21037/cco-21-69 state transitions give rise to phenotypic equilibrium in populations of cancer cells. Cell 2011;146:633-44.

68. Mansoori B, Mohammadi A, Davudian S, et al. The Different Mechanisms of Cancer Drug Resistance: A Brief Review. Adv Pharm Bull 2017;7:339-48.

69. Barcellos-Hoff MH, Park C, Wright EG. Radiation and the microenvironment - tumorigenesis and therapy. Nat Rev Cancer 2005;5:867-75.

70. Mirzayans R, Andrais B, Scott A, et al. Multinucleated Giant Cancer Cells Produced in Response to Ionizing Radiation Retain Viability and Replicate Their Genome. Int J Mol Sci 2017;18:360.

71. Vilalta M, Rafat M, Graves EE. Effects of radiation on metastasis and tumor cell migration. Cell Mol Life Sci 2016;73:2999-3007.

72. Nowell PC. The clonal evolution of tumor cell populations. Science 1976;194:23-8.

73. Lazova R, Laberge GS, Duvall E, et al. A Melanoma Brain Metastasis with a Donor-Patient Hybrid Genome following Bone Marrow Transplantation: First Evidence for Fusion in Human Cancer. PLoS One 2013;8:e66731.

74. LaBerge GS, Duvall E, Grasmick Z, et al. A Melanoma Lymph Node Metastasis with a Donor-Patient Hybrid Genome following Bone Marrow Transplantation: A Second Case of Leucocyte-Tumor Cell Hybridization in Cancer Metastasis. PLoS One 2017;12:e0168581.

75. Vincent TL, Gatenby RA. An evolutionary model for initiation, promotion, and progression in carcinogenesis. Int J Oncol 2008;32:729-37.

76. Gatenby RA, Vincent TL. An evolutionary model of carcinogenesis. Cancer Res 2003;63:6212-20. 